\title{
A RARE CASE OF BURKITT'S LYMPHOMA
}

\author{
Mansi Jain'1, Sanjay Nigam², Ankita Jaiswal ${ }^{3}$, Supriya Katiyar ${ }^{4}$, Renu Jain ${ }^{5}$
}

1 Postgraduate, Department of Pathology, Rama Medical College Hospital and Research Centre, Mandhana, Kanpur.

2Professor, Department of Pathology, Rama Medical College Hospital and Research Centre, Mandhana, Kanpur.

3Senior Resident, Department of Pathology, MAMC, New Delhi.

${ }^{4}$ Assistant Professor, Department of Pathology, Rama Medical College Hospital and Research Centre, Mandhana, Kanpur.

5 Professor and HOD, Department of Pathology, Rama Medical College Hospital and Research Centre, Mandhana, Kanpur.

ABSTRACT

\section{BACKGROUND}

Burkitt's lymphoma is a malignant tumour of lymphatic system that originates from B lymphocytes in germinal centre of lymph nodes. Malignant tumours of head and neck in children are rare. Here, we present a rare case of 5-year-old male child with Burkitt's lymphoma of craniofacial localisation. The child presented with complaints of painless swelling and erythema of the right cheek that persisted for a week. Examination revealed oedema and erythema of the right cheek, neck lymphadenopathy with no other abnormalities. Ultrasonography of the cheek showed hyperechogenic, hyperaemic area within soft tissues of the cheek with irregular fluid spaces and enlarged lymph nodes within the right parotid gland and in the neck. Biopsy was done and histopathology was suggestive of Burkitt's lymphoma.

\section{KEYWORDS}

Burkitt's Lymphoma, Epstein-Barr Virus, Starry Sky Pattern, Children, Chemotherapy.

HOW TO CITE THIS ARTICLE: Jain M, Nigam S, Jaiswal A, et al. A rare case of Burkitt's lymphoma. J. Evolution Med. Dent. Sci. 2016;5(80):6011-6013, DOI: 10.14260/jemds/2016/1357

\section{INTRODUCTION \\ Burkitt's lymphoma is recognised as a rapidly dividing, highly} malignant B-cell non-Hodgkin's lymphoma composed of very uniform small transformed (Small non-cleaved) B cells with a distinct phenotype and an MYC translocation.(1) Burkitt's lymphoma can be divided into three main clinical types: Endemic, Sporadic and Immunodeficiency.

The endemic variant, also known as African variant, occurs mainly in children living in malaria endemic regions of the world, e.g. Africa, Brazil. In almost all patients with this variant Epstein-Barr virus is found. The disease involves jaw or other facial bones.

The sporadic type is the most common one in the places where malaria is not endemic. In this variant, EBV association is rare. The sporadic Burkitt's lymphoma involves mainly ileocaecal region.

Immunodeficiency associated Burkitt's lymphoma occurs usually in immunocompromised patients with HIV infection or after organ transplant.(2,3)

There can be a spectrum of presenting symptoms of Burkitt's lymphoma; hence, the diagnostic procedures depend on signs and symptoms of the patient. Burkitt's lymphoma treatment consists of chemotherapy.

\section{CASE REPORT}

A 5-year-old male patient presented with painless swelling and erythema of the right cheek for 1 week. On examination there was oedema and erythema of the right cheek, enlarged

Financial or Other, Competing Interest: None.

Submission 22-08-2016, Peer Review 23-09-2016,

Acceptance 28-09-2016, Published 06-10-2016.

Corresponding Author:

Dr. Mansi Jain,

Postgraduate, Department of Pathology,

Rama Medical College Hospital \& Research Centre,

Mandhana, Kanpur-209217, U. P.

E-mail: jainmansi3590@gmail.com

DOI: $10.14260 /$ jemds/2016/1357

\section{(c) $(\mathrm{P})($}

parotid gland along with neck lymphadenopathy. No other abnormalities were seen. Antibiotics were given, but there was no improvement in the condition of the patient. Ultrasonography of the cheek showed hyperechogenic hyperaemic area within soft tissues of the cheek with irregular spaces filled with fluid. There were enlarged lymph nodes involving the right parotid gland and neck. It was diagnosed as Burkitt's lymphoma on histopathology excluding squamous cell carcinoma and mucoepidermoid carcinoma. Patient underwent multidrug chemotherapy. After 2 months CT scan was performed, which showed regression of the tumour in craniofacial area as well as of lymph nodes of parotid gland and neck. Patient was advised to follow up after 6 months.

\section{Histopathological, Cytological and Immunophenotype Finding}

Burkitt's lymphoma shows architectural effacement in most cases. The tumour exhibits a high mitotic index and contains benign macrophages also known as tingible body macrophages. These phagocytes have abundant clear cytoplasm, creating a characteristic "Starry sky pattern." Usually markers positive in Burkitt's lymphoma are CD19, CD20, CD10 and BCL6; whereas 100\% of tumour cell nuclei are Ki-67 positive.

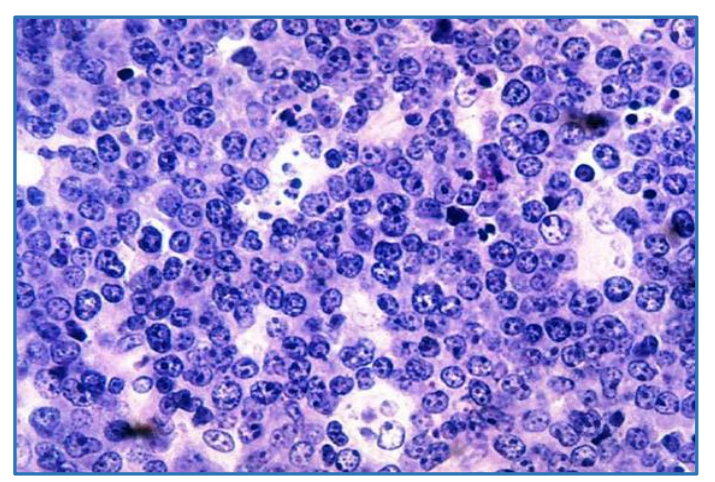

Fig. 1: Photomicrograph showing an H\&E Stained Slide showing Starry Sky Appearance under High Magnification (40x) 


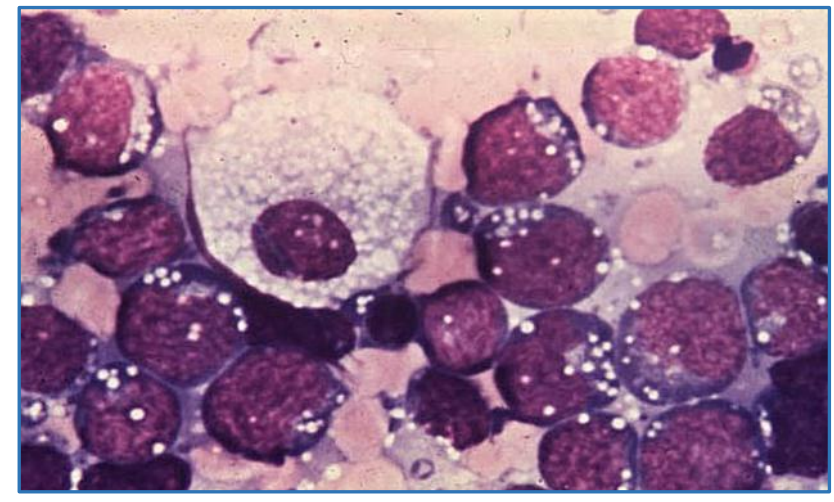

Fig. 2: Photomicrograph showing MGG Stained Slide showing Round Lymphoid Cells, Variation in Nuclear Size, Distinct Nucleoli, Granular Chromatin, Dense Blue Cytoplasm with Lipid Vacuoles and some Starry Sky Macrophages (400x)

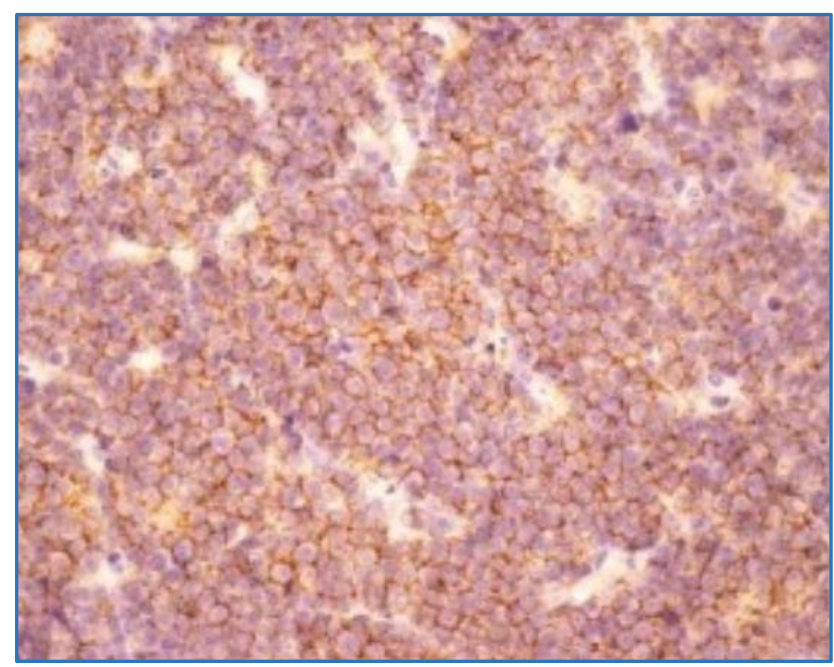

Fig. 3: Photomicrograph of IHC showing Positive Result for CD10 Marker

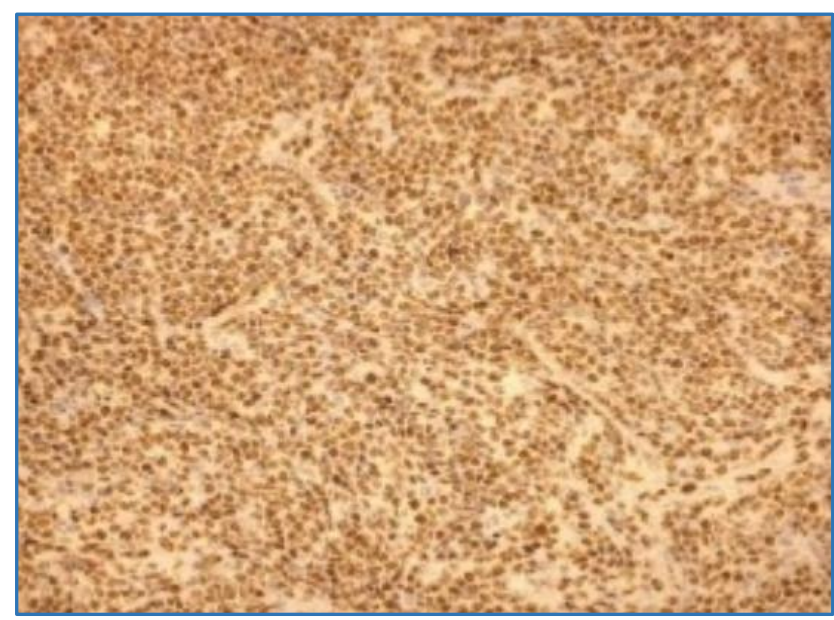

Fig. 4: Photomicrograph of IHC showing Positive Result for Ki-67 Marker (100x)

In the present study at my centre, the facilities for all the markers were not available. So only CD10 and Ki-67 markers were performed, which were positive.

\section{DISCUSSION}

Burkitt's lymphoma is a very aggressive, but potentially curable lymphoma.(4) Only about $5 \%$ to $10 \%$ of primary malignant conditions in the paediatric group originate in the head and neck. $(5,6)$ Non-Hodgkin's lymphoma has an occurrence rate of about $26 \%$ in paediatric head and neck malignancies. ${ }^{7,8)}$ It was first reported in 1958 by a British missionary surgeon, Sir Dennis Burkitt, who described a multifocal tumour syndrome that involved expansion of the jaws accompanied by loosening and irregular displacement of teeth.(9) Clinically, jaw and midfacial lesions appear to dominate the endemic forms of the disease, whereas abdominal (Ileocaecal) involvement is seen in the sporadic type.(10) In head and neck area, Burkitt's lymphoma frequently involves the cervical lymph nodes. It can also have a leukaemic presentation.

Most cases occur in patients younger than 10 years of age. Mean age of involvement in endemic variety is 7 years and in sporadic variety is 11 years. There is peak incidence between ages 5 and 7 years.(11) Both endemic and sporadic types affect boys twice as many as girls.

In the present study, the cytological and histopathological detailing was done and on morphology squamous cell carcinoma and mucoepidermoid carcinoma were excluded. The markers performed were only two, i.e. CD10 and Ki-67 due to lack of facilities.

Fine needle aspiration is generally inadequate for the diagnosis. Open biopsy is necessary to obtain adequate tissue for appropriate immunohistochemical studies. Imaging procedures such as CT and MRI can help to determine the extent of the primary disease.

Burkitt's lymphoma ranks among the fastest growing of all human tumours and needs prompt intervention. It spreads by blood dissemination. The primary therapeutic modality for Burkitt's lymphoma is chemotherapy.

\section{CONCLUSION}

Malignant tumours of head and neck in children are rare. Primary symptoms of Burkitt's lymphoma can be localised in craniofacial region excluding squamous cell carcinoma and mucoepidermoid carcinoma. Thus, especially general practitioners and paediatricians should be aware of careful diagnostic procedures and treatment in these patients. CT scan should be performed in case of any non-specific anomaly in head area. Chemotherapy is the treatment of choice in Burkitt's lymphoma.

\section{REFERENCES}

1. Leoncini L, Raphael M, Stein H, et al. Burkitt lymphoma. In: Swerdlow SH, Campo E, Harris NL, et al, eds. WHO Classification of tumors of haemopoitic and lymphoid tissues. Lyon, France: IARC Press 2008:262-4.

2. Chen DT, Chen PR, Hsu LP, et al. Burkitt's Lymphoma in paranasal sinuses. Otolaryngol Head Neck Surg 2006;135(6):991-3.

3. Nikgoo A, Mirafshariyeh SA, Kazeminajad B, et al. Burkitt's lymphoma of maxillary sinuses: review of literature and report of bilateral case. J Oral Maxillofac Surg 2009;67(8): 1755-63.

4. Sandlund JT, Downing JR, Crist WM. Non-Hodgkin's lymphoma in childhood. N Engl J Med 1996;334(19): 1238-48.

5. Wang M, Strasnick B, Zimmerman MC, et al. Extranodal American Burkitt's lymphoma of the head and neck. Arch Otol Head Neck Surgery 1992;118(2):193-9. 
6. Weisberger EC, Davidson DD. Unusual presentations of lymphoma of the head and neck in childhood. Laryngoscope 1990;100(4):337-42.

7. Gaini RM, Romagnolia M, Sala A, et al. Lymphomas of head and neck in pediatric patients. Int J Pediatr Otorhinolaryngol 2009;73(Suppl 1):S65-70.

8. Roh JL, Huh J, Moon HN. Lymphomas of head and neck in the pediatric population. Int J Pediatr Otorhinolaryngol 2007;71(9):1471-7.
9. Nissenbaum M, Kaban LB, Troulis MJ. Toothache, paresthesia and horner syndrome: an unusual presentation of disseminated Burkitt's lymphoma. J Oral Maxillofac Surg 2007;65(7):1395-401.

10. Mawardi H, Cutler C, Treister N. Medical management update: Non- Hodgkin lymphoma. Oral Surgery Oral Med Oral Pathol Oral Radiol Endod 2009;107(1):e19-33.

11. Lund DI, Rodd H, Craig GT. Burkitt's lymphoma presenting with jaw lesions in a young white girl. J Oral Maxillofac Surg 1997;35(6):438-41. 